\title{
ACERCA DE LAS PRESENTACIONES EN EL VII SIMPOSIO-TALLER DE ICTIOLOGIA
}

\author{
ON THE PAPERS PRESENTED AT THE VII SYMPOSIUM-WORKSHOP OF \\ ICHTHYOLOGY
}

\author{
Germán Pequeño
}

Instituto de Zoología, Universidad Austral de Chile, Casilla 567, Valdivia, Chile. email: gpequeno@uach.cl

El VII Simposio-Taller de Ictiología, auspiciado por la Asociación Chilena de Ictiología (ACHI) y organizado por la Universidad Austral de Chile, tuvo lugar en la ciudad de Valdivia, entre los días 14 y 16 de enero del año 2004. En esa oportunidad, además, tal Asociación celebró 25 años de vida. Los Socios, entre otras materias, discutieron la necesidad de incrementar la tasa de publicaciones, teniendo en especial consideración que un alto número de las presentaciones en congresos, simposios y similares nunca superan esa etapa de presentación pública. En otras palabras, hay un importante porcentaje de la "productividad" científica, que pese a haber ocurrido, pasa al sector de los conocimientos inaccesibles, talvez lo más recóndito de la llamada información gris.

Decididos a disminuir el problema descrito, los asistentes al VII Simposio-Taller acordaron hacer esfuerzos por publicar los trabajos allí presentados, que en total alcanzaron 29, ocho de los cuales correspondieron a Chondrichthyes y el resto a Osteichthyes. Se recordó que con motivo del VI Simposio-Taller, Gayana dio la posibilidad de publicar aquellas presentaciones hechas el año 2002. Naturalmente, la invitación se hizo en el marco de las normas y exigencias editoriales que caracterizan a Gayana. La ACHI acogió con entusiasmo tal invitación e instó a los participantes de entonces a enviar sus manuscritos, de acuerdo con las "Instrucciones" públicamente conocidas. El proceso fue un éxito y en el volumen 66(2) del año 2002 de Gayana, aparecieron 15 artículos -incluyendo la figura del pez que representa a la Asociación en la portada- y un Comentario Editorial, que dan cuenta de los primeros esfuerzos concertados para publicar (proceso de arbitraje de por medio) los resultados presentados en reuniones científicas.

Con motivo del VII Simposio-Taller se ha repetido el proceso. Los resultados están en vuestras manos y no se requiere repetir cómo ha sido el origen de esta iniciativa, pues es análoga a la tenida con el VI
Simposio-Taller. La ACHI no puede sino agradecer lo que considera un adecuado criterio editorial. Hay convicción en la potencialidad mayor que se consigue aunando esfuerzos entre sociedades científicas y editores, como es este caso. Enhorabuena por las ciencias, especialmente en un país donde su comprensión y práctica parecen estar sufriendo un proceso lamentablemente regresivo donde hay que esforzarse más para que la gente se "encante" con ellas, para que se tenga más confianza en ellas y también en los científicos. Aunque el número de trabajos ahora es menor, ello no debe atribuirse a falta de interés o cosas por el estilo, sino a que varios autores han tenido compromisos previos para publicar sus resultados en otras revistas, lo cual es también plausible, porque se está logrando objetivos análogos a los aquí señalados, aunque ello "disperse" un poco la información, cosa que justamente aquí hemos tratado de subsanar.

La ictiología es una ciencia que, mirando a su alrededor con irrenunciable respeto, sabe que tiene enormes responsabilidades, dada la importancia que los peces tienen en el ámbito de vida del pueblo chileno. Los ictiólogos sabemos que, "dependiendo del cristal con que se mire”, hay ángulos que señalan que sobre ciertos peces "se sabe bastante", en cambio sobre la gran mayoría apenas se conocen sus binomios en actualizado latín. Por esto, el apoyo de Gayana ha encontrado tan buena acogida en la ACHI. Esperamos que el esfuerzo realizado sea un estímulo, no solamente para los autores que han publicado ahora, sino también para aquellos que lleven presentaciones al VIII Simposio-Taller, a efectuarse en enero del año 2006. Ya no sólo es cuestión de necesidad e interés de Gayana y de la Asociación. Es que se ha transformado en una valiosa herramienta -construida precisamente para eso- para contribuir a la edificación de nuestra educación, de una cultura que se hace minuto a minuto, día a día, año a año y a la cual hemos decidido sumarnos, porque es la base del futuro, sin más explicaciones. 